\title{
$\mathrm{X}$ 線撮影における斜入効果と幾何学的不鋭
}

宮崎医科大学医学部附属病院放射線部

稲津博

（論支受付 昭和51年11月13日）

(Code No. 21123)

\section{OBLIQUE INCIDENCE EFFECT AND GEOMETRIC UNSHARPNESS IN RADIOGRAPH}

\section{By HiRoshi InATSU}

Department of Radiology, Medical College of Miyazaki

(Article received: Nov. 13, 1976)

\section{Summary}

In this study, the modulation transfer function (MTF) of oblique incidence effect and the MTF of geometric unsharpness were investigated. The MTF of oblique incidence effect is dependent upon the angle at which an X-ray beam is incident on a screen-film system, and the greater incidence angle get, the lower the MTF make. In addition, spurious resolution is produced at an angle of almost $20^{\circ}$.

The total MTF is the sum of MTF of recording system and MTF of geometric unsharpness.

The total MTFs of magnification factor 1.1 at an incidence angle of $30^{\circ}$ and magnification factor 1.2 at an incidence angle perpendicular to the screen-film system were compared. These total MTF have approximatery equal value with $1.3 \mathrm{~mm}$ focal spot employed.

However, if a focal spot smaller than $1.3 \mathrm{~mm}$ is employed, the total MTF of magnification factor 1.2 at an incidence angle perpendicular to the screen-film system is better than the total MTF of magnification factor 1.1 at an incidence angle of $30^{\circ}$.

\section{1. 緒言}

人体のある部分のX線写真像を得ようとするとき， た の目的，部位によって中心X線を screen-film 系に対し て斜入させることがある。このような方法で作成された $\mathrm{X}$ 線写真像は，X線 film がある厚さを持ち，前後面 2 枚の增感紙によって像が形成されるため，中心X線を重 直に入射させて作成したX線写真像より鮮鋭度は劣化し ている.
X線斜入による影響は被写体に角度を持たせることに よっておきかえることができる。

しかし，被写体に角度を持たせることで，必然的に被 写体 - film 間距離が大きくなり拉大によるボヶが生じる. X線斜入の方法と被写体に角度を持たせる方法はX線斜 入効果之㹡大効果の空間周波数特性によって比較するこ とができる.

本論文では，X線斜入によるボケと昖大によるボケを 比䡆検討し，その得失を論じる. 


\section{X 線斜入による Screen-film 系のボケ}

一般に医療用X線 film は支持体の両面に乳䠼を塗布 し，2枚の増感紙で㣣えで使用する．乙のため，X線が 斜入することによって增感紙には Front と Back 亿2つ の像, film 亿は Front と Backの2つの像が生じる. Fig.1(a)，（b）はそれぞれ screen-film 系にX線が垂 直および斜入するときの線像強度分布を示す。いま増感 紙の線像強度分布および film の線像強度分布の Front 側およびBack 側それぞれの和を $F f(x), F b(x)$ とす れば全体の線像強度分布 $F(x)$ は，

$$
F(x)=F_{f}(x)+F_{b}(x)
$$

となる゙!

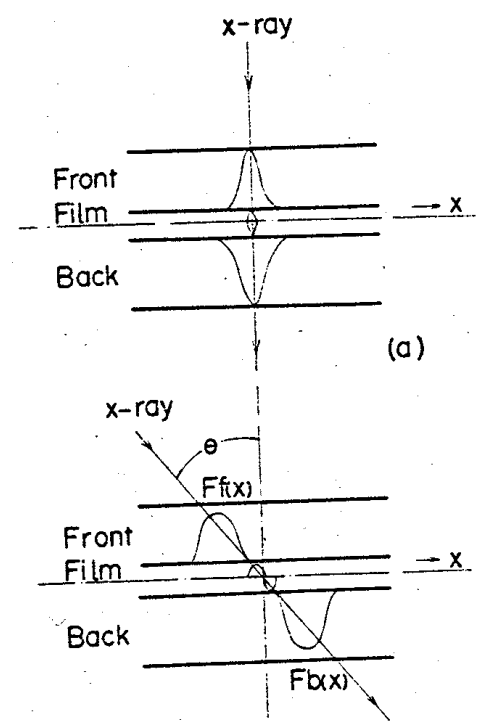

(b)

Fig. 1. Line spread functions by X-ray which enter perpendicular and oblique incidence to screen-film system.

\section{X 線管焦点の画像への影響}

$\mathrm{X}$ 線管焦点の画像への影暨はX線管焦点の空間周波数

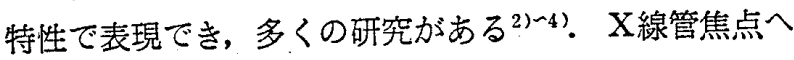
の影響は幾何学的配置，画角特性などがあるがここでは 幾何学的不鋭について考える.

幾何学的不鋭とX線管焦点の関係は簡単に考えるとつ ぎのようになる。

いま被写体拡大率を $\mathrm{m}$ とし，焦点一被写体間距離を $\mathrm{a}$ ， 被写体一像面間距離を $\mathrm{b}$ とすれば， $\mathrm{m}=1+(\mathrm{b} / \mathrm{a})$ とな る. 被写体拡大率 $\mathrm{m}$ のをきの像面におけるX線管焦点の 空間周波数特性は, 焦点面にお汀る空間周波数特性の横 軸（空間周波数）をb/a で割算することによって得ら れる4).

\section{4. 穾験および結果}

実験に使用したX線発生装置は単相全波整流，X線管 は回転晹極，公称焦点寸法 $1 \times 1 \mathrm{~mm}$ を使用した，增感 紙は $\mathrm{CaWO}_{4}$ 中感度增感紙，film は普通感度 filmを使用 した。

焦点 - film 間距雦は $200 \mathrm{~cm}$ とし, Cassette 前面に矩 形波 chartを置いてX線を照射した．X線入射角度は $0^{\circ}, 10^{\circ}, 20^{\circ}, 30^{\circ}, 40^{\circ}$ (cassette 任垂直に入射するときを $0^{\circ}$ とし，垂直軸からの傾きを表わす）とした．撮影さ れた chart 像は Microdensitometer で走查し, film 濃度 は有效露光量汇変換して空間周波数特性 (MTF) を求め た.それぞれの入射角度による MTFを Fig. 2に示す。

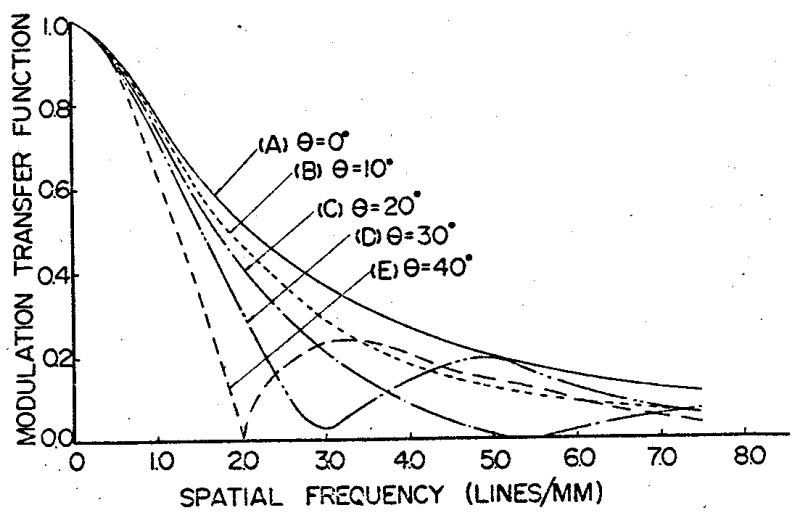

Fig. 2. The MTFs of oblique incidence effect.

A) Incidence angle of $0^{\circ}$.

B) Incidence angle of $10^{\circ}$.

C) Incidence angle of $20^{\circ}$.

D) Incidence angle of $30^{\circ}$.

E) Incidence angle of $40^{\circ}$.

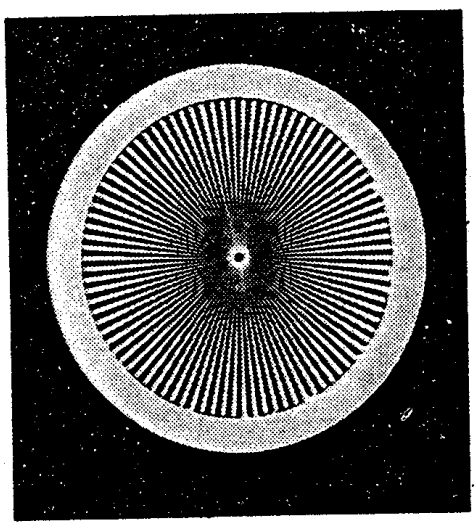

Fig. 3. Photograph of spurious resolution at a incidence angle of $40^{\circ}$. 
入射角度が大きくなるにつれて screen-film 系の MTF は悪くなる. また $20^{\circ}$ から偽解像が生じる. 入射角 $40^{\circ}$ 亿おける儒解像のようすを Fig. 3 亿示 す.

実験使用した公称 $1 \times 1 \mathrm{~mm}$ 焦点のそれぞれの 幾何学的配置における不鋭を Fig. 4 亿示す. Fig. 4 はX線管短軸方向の特性を示し, 測定は矩形波 chart 法で実測した。

Fig. 4 から应大率が大きくなると急速 MTF が劣 化することがわかる．矩形波 chart の線対が消える 部分の線対の中から計算された本実験に使用したX 線管の実際の焦点寸法は約 $1.3 \mathrm{~mm}$ である゙

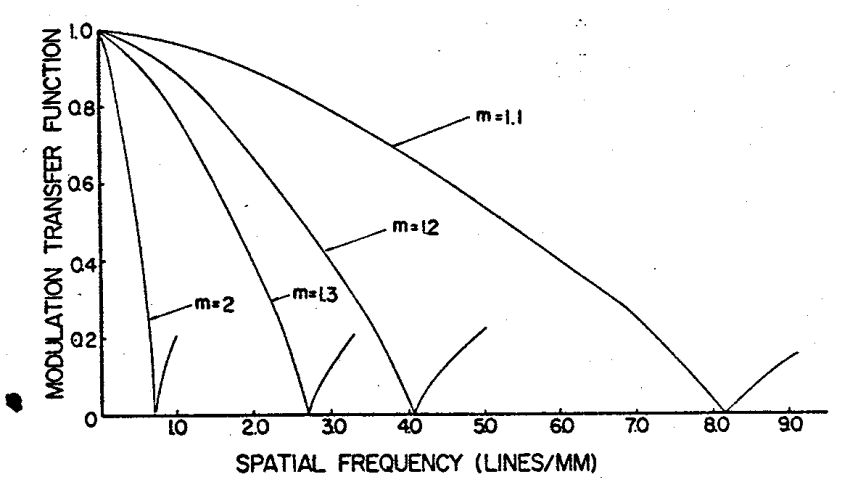

Fig. 4. MTFs of geometric unsharpness by focal spot employed at expriment. (Nominal focal spot size $1 \times 1 \mathrm{~mm}$ )

\section{5. 考察}

X線が screen-film 系汇対し 斜入したときの線像強度 分布 (LSF) の形状は入射角度, 螢光物質とX線 film の 厚さに依存する゙!。文，入射角 $30^{\circ}$ の線像強度分布を

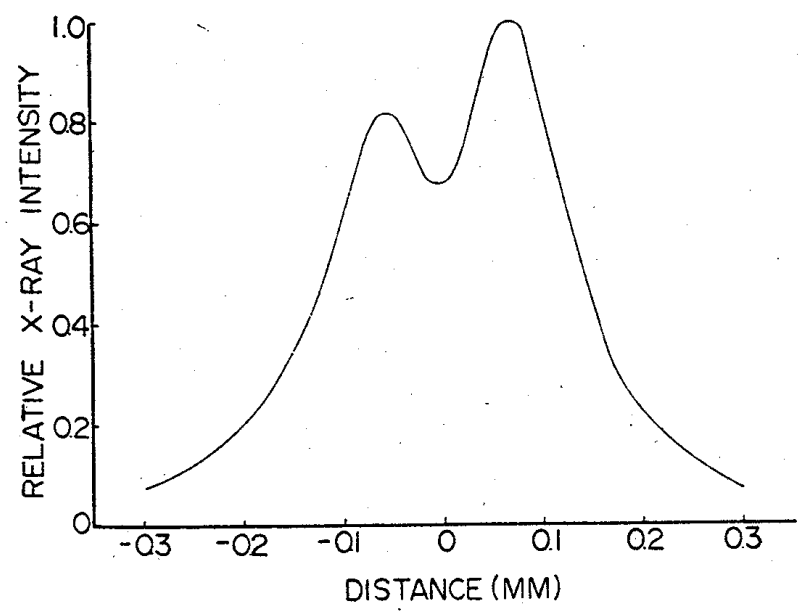

Fig. 5. X-ray intensity distribution in the case of $\mathrm{X}$-ray entering obliquely into screenfilm system at an angle of $30^{\circ}$.

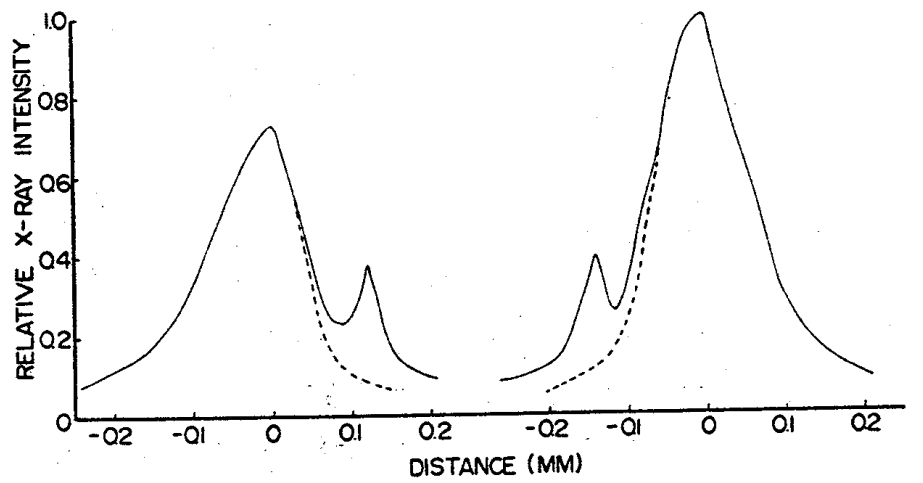

(a)

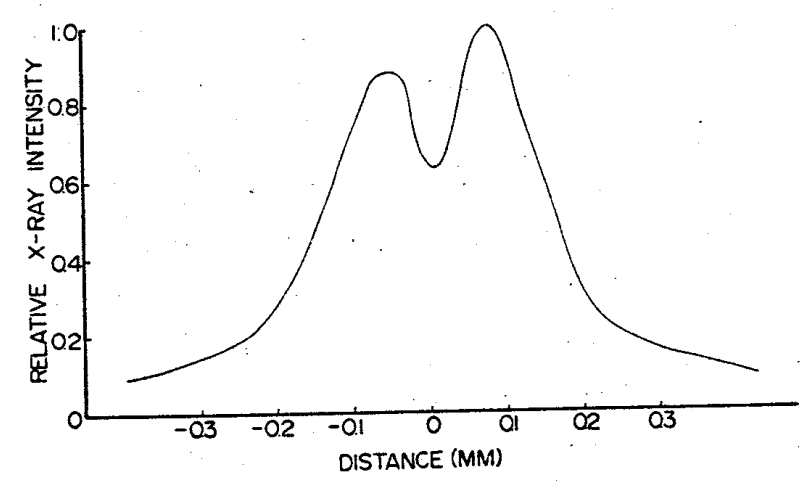

(b)

Fig. 6. $\mathrm{X}$-ray intensity distribution in the case of X-ray entering obliquely into front screen-film and back screen-film system respectively, and X-ray intensity distribution obtained from Equation 1.

調べるとFig. 5 亿示すような形状を示す.

発光 peak ( 2 つ出) の間滆は約 $0.125 \mathrm{~mm}$ である. したがって, てのととは約 $0.216 \mathrm{~mm}$ 厚さの物質によっ て発光 peakが搹てられていることを幾何学的㐳示して いる.

この厚さはほぼ実験化使用したX線 filmの厚さに相 当する. これらのととから最す重要な增感紙の発光部分 は增感紙のごく表面（film）に存在するととがわかる.

Fig. 6 亿入射角 $30^{\circ}$ で Front および Back 增惑紙によ ってX線 film 乳凨中に生じた LSF（Fig. 6 a) と，てれ を(1)式によって合成して得られた分布を示す. 实験は film の片面を黒紙でおおって Cassette に扱入し Slit 像 を撮影する方法を用いた。したがって，Front 增感紙側 の film 強度分布は Front 増感絓発光分布の中に含まれ, Back 增感紙㑡の film 強度分布が小さなPeak として現 われている. Back 側増感紙関しても同じである.

Fig. 6 において Front と Backを合成するときは Front と Back の線像强度分布が点線で示すような分布 
になる。

X線斜入による鮮鋭度の悪化に防ぐためには，被写体 に角度を持たせて screen-film 系にX線束を垂直に入射 させればよい。

しかし被写体を覑斜させると一般に挔大率が増加して 鮮鋭度は悪くなる。いま実験に用いたX線管を使用して 焦点 - film 間距離 $100 \mathrm{~cm}$ で撮影するときを考える.X 線斜入撮影で目的部位は Cassette 面から $9.1 \mathrm{~cm}$ (搪大 率1.1)，斜入効果を除くためX線を垂直に入射させると $16.7 \mathrm{~cm}$ (拡大率1.2）となると仮定する. 乙の仮定は ぼ Towne 法で鞍背および内耳孔を観察することに相当 する. とのとき screen-film 系と幾何学的状態だけを考 え，他のすへての因子は雨方法とも同一と仮定し，入射 角度は $30^{\circ}$ を例得々。．前述の系は直列な系であるから 総合の系の MTF はそれぞれの MTF の積で表わされる. したがって，両系の総合の MTF は Fig.7亿示すような あのとなる．MTF は両系とす低周波ではほぼ同一の値 を示すが，高周波になるにしたがって垂直入射した方が 勝れている. また斜入代よる像の歪汇関する点です被写 体に角度を持たせた方が勝れていると考えられる. 焦点 寸法，拉大率，入射角度それそれれが変化したときの空間 周波数 1.5 lines $/ \mathrm{mm}$ における総合の系の MTF を Fig. 8 亿示す.

空間周波数 1.5 lines $/ \mathrm{mm}$ を選んだ理由は 1.0 lines/ $\mathrm{mm}$ では MTF がそれほど変化しなく, 2.0 lines/mmで は入射角 $40^{\circ}$ でMTFが 0 となるためである. Fig. 8か ら前述のような仮定のとき, 焦点寸法が小さくなれば垂

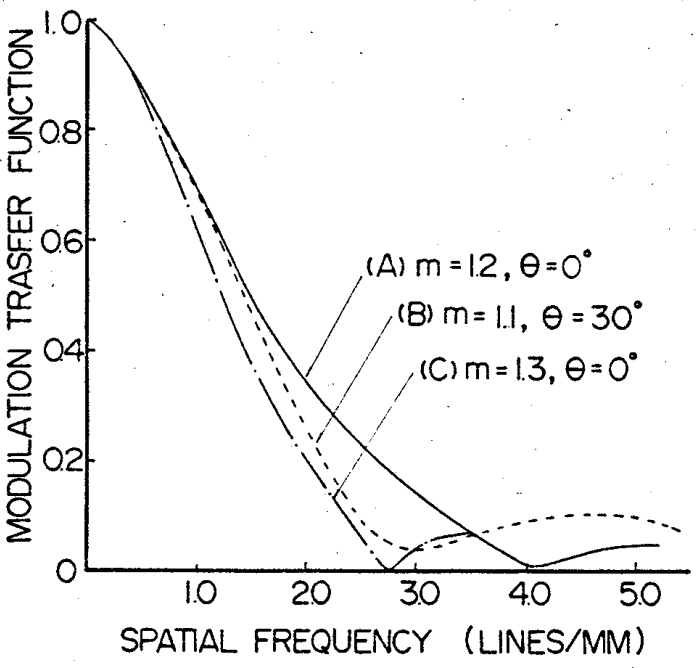

Fig. 7. The comparison of the MTFs between the magnification factor 1.1 at an inci. dence angle of $30^{\circ}$ and magnification factor 1.2 at an incidence angle perpendicular to the screen-film system.

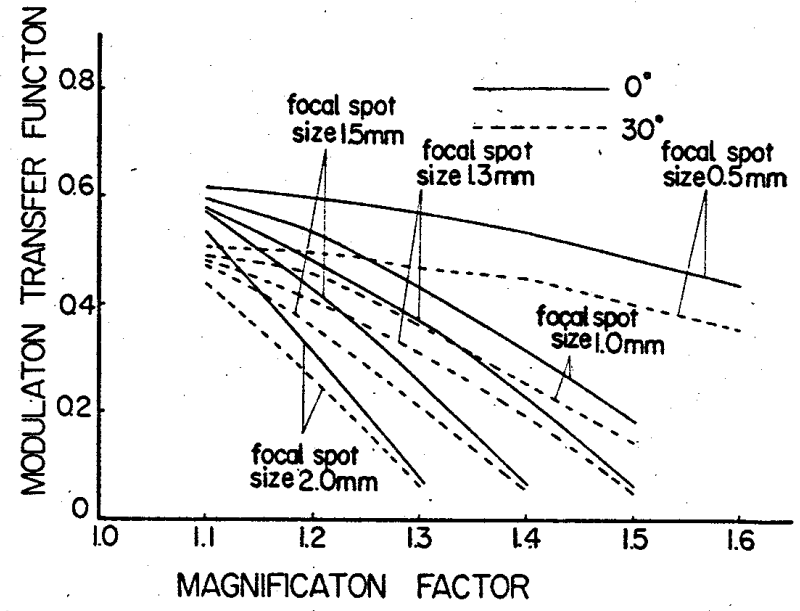

Fig. 8. The relation of geometric conditions anả focal spot size at 1.5 lines $/ \mathrm{mm}$.

直入射の $\mathrm{X}$ 線写真の方が $\mathrm{X}$ 線斜入 $\mathrm{X}$ 線写真より勝れてい ることがわかる. また， $0.5 \mathrm{~mm}$ 焦点において入射角 $30^{\circ}$ ， 抬大率1.1で撮影する方法より垂直入射, 挔大率1.4の方 が良い結果を示す. 反対に $2 \mathrm{~mm}$ 焦点では垂直入射, 拡 大率1.2では悪い結果を示す.

このことはX線管焦点寸法によって入射X線に角度を 持たせるか, 被写体に角度を持たせるかを決定するべき であることを示している. Fig. 8 亿おける焦点の MTF は表示された焦点寸法を持つ矩形波と仮定して計算した 值である.

\section{6. 結 語}

前述の上うにX線写真の鮮鋭度は入射角度、焦点寸法, 拡大率など幾何学的状態によって变化する. 現在のX線 写真撮影法の大部分は古くから用いられているものであ る.

したがって幾何学的条件もかなり悪かったてとと思わ れる. しかし現在では高感度 system が開発され， 3 倍 回転X線管む使用されるようになり比較的良い幾何学的 条件で撮影するてとが可能となったしたがって 5 項で 述べたように入射角度によっては垂㨁入射X線写真の方 が鮮鋭度として勝れているときがある. てのことは機器 の進歩を考慮した撮影法の再検討が必要であるととを示 している.

本研究の遂行にあたり終始御指遵をいただいた岐皁大 学工学部教授, 内田勝博士に深く感謝致します。

\section{文献}

1）内田 勝: 断層撮影像のボケのフーリエ解析, 応用 物理, $35,10,1966$. 
2) 内田 勝: X線管焦点のX線強度分布のフーリエ解 析, 34, 2, 1965.

3）土井邦雄：X線撮影系のレスポンス関数 (II) X線 管焦点, 故射線像の研究, 第 1 巻.
4）金森仁志：X線管焦点のレスポンス関数，放射線像 の研究，第 1 巻.

5）稻津 博他：X線管焦点寸法の管電流による変化, 日放技学会誌，29，3，1973.

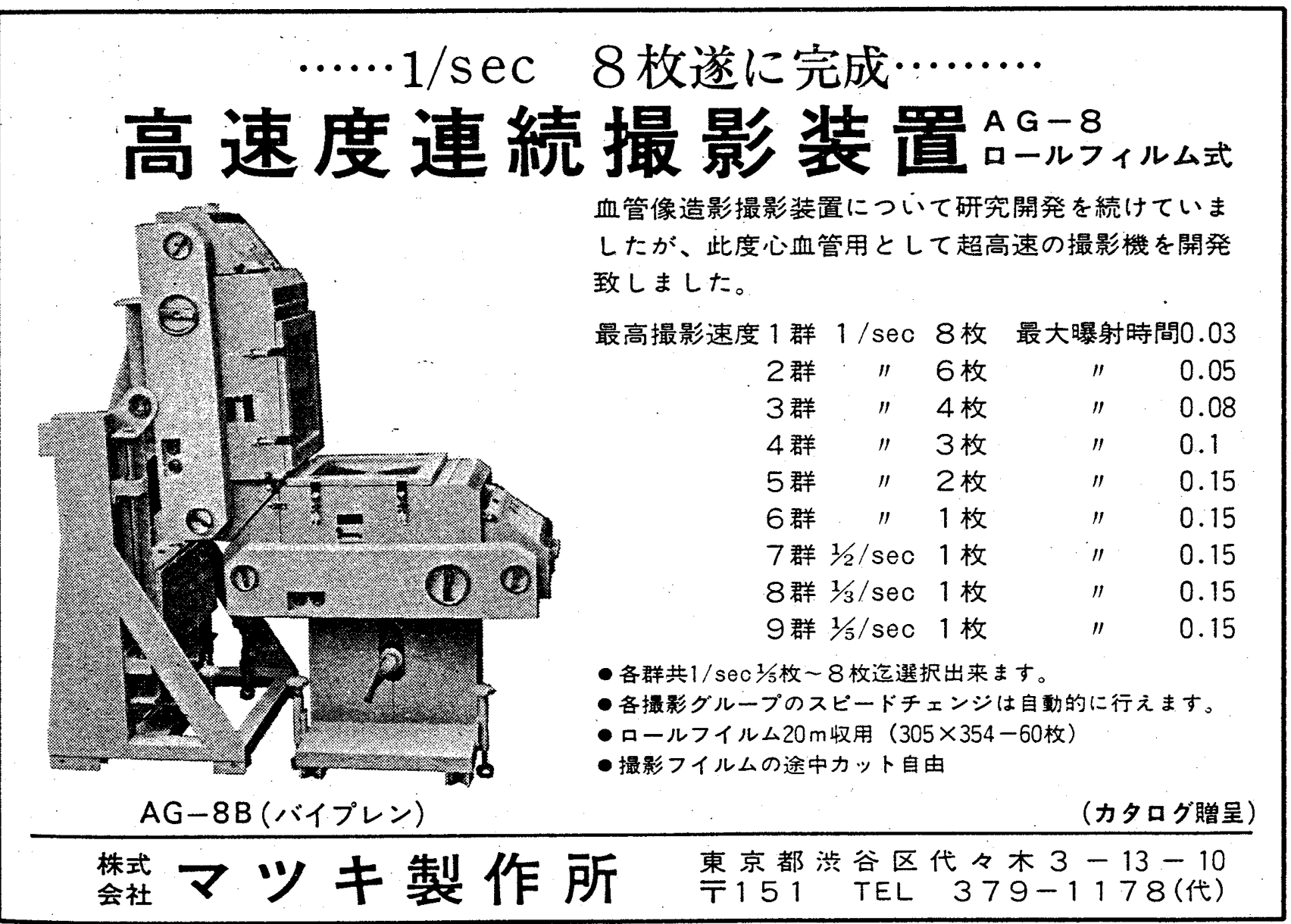

